\title{
Sexual side-effects of antidepressant and antipsychotic drugs
}

\author{
David Baldwin \& Andrew Mayers
}

Abstract Adequate sexual expression is essential to many human relationships and provides a sense of physical, psychological and social well-being. Epidemiological and clinical studies show that depression and schizophrenia are associated with impairment of sexual function and satisfaction, even in untreated patients. Most antidepressant and antipsychotic drugs have adverse sexual effects but it is difficult accurately to identify the incidence of treatment-emergent dysfunction, as disturbances can be reliably detected only from systematic enquiries made at baseline and during treatment. Growing awareness of the adverse effects of psychotropic drugs has led to attempts to use adjuvants or substitute treatments to resolve sexual dysfunction. More studies of the effects of antidepressant and antipsychotic drugs on sexual function are needed.

The normal sexual response is conventionally divided into the four phases listed below, and disorders can occur at one or more of these phases.

(1) Desire: typically this consists of fantasies about, and the desire to have, sexual activity.

(2) Excitement: a subjective sense of sexual pleasure and accompanying physiological changes, namely penile tumescence and erection in men and pelvic vasocongestion, swelling of the external genitalia, vaginal lubrication and expansion in women.

(3) Orgasm: this is when sexual pleasure peaks, with release of sexual tension and rhythmic contraction of the perineal muscles and reproductive organs. In men, the sensation of ejaculatory inevitability is followed by ejaculation of semen. In women, contractions of the outer third of the vaginal wall occur.

(4) Resolution: a sense of muscular relaxation and general well-being. Men are physiologically refractory to erection and orgasm for a variable period after orgasm, whereas women may respond to further stimulation.

The ICD-10 (World Health Organization, 1992) uses the term 'sexual dysfunction' to cover the ways in which an individual is unable to participate in a sexual relationship as he or she would wish. This classification has 10 subdivisions (F52.0-F52.9), each describing different forms of dysfunction. The DSM-IV (American Psychiatric Association, 1994) uses a similar scheme. Whenever possible, doctors should specify which form of sexual dysfunction is present, as these have differing causes and require different treatment approaches.

Some types of dysfunction occur in both men and women, although women tend to present with complaints about the subjective quality of sexual experience (e.g. lack of desire), whereas men often describe the failure of a specific response (such as erection) but a continuing sexual desire.

\section{Epidemiology of sexual dysfunction}

This area has not been studied extensively. Nathan (1986) evaluated 22 studies of sexual behaviour in the general population but concluded that methodological problems in the surveys meant that only broad estimates could be made. The prevalence of inhibited sexual desire was $16 \%$ for men, $35 \%$ for women; for erectile dysfunction and premature ejaculation the prevalence values were $10-20 \%$ and $35 \%$ of men, respectively; female orgasmic difficulties had a prevalence of $5-15 \%$.

David Baldwin is a senior lecturer in psychiatry and honorary consultant psychiatrist at the Royal South Hants Hospital, University of Southampton (University Department of Mental Health, Brintons Terrace, Southampton SO14 0YG, UK. Tel: (0)2380 825533; fax: (0)2380 234243; e-mail: dsb1@soton.ac.uk). His research interests include the treatment of depression and anxiety disorders, sexual dysfunction and the prevention of suicidal behaviour. He has acted as an advisor to pharmaceutical companies that manufacture antidepressant or antipsychotic drugs. Andrew Mayers is a research psychologist at the Royal South Hants Hospital, University of Southampton. His research interests include depression, anxiety disorders, suicide and sleep. The University of Southampton has received grants from pharmaceutical companies to support research into the relationships between mental health problems and their treatment and sexual dysfunction. 
A US study found that sexual dysfunction in the general population is more prevalent in women $(43 \%)$ than men $(31 \%)$ (Laumann et al, 1999). Using latent class analysis, symptoms during the previous 12 months could be grouped into three categories. In women, these were low sexual desire $(22 \%$ prevalence), arousal or excitement problems (14\%) and sexual pain $(7 \%)$; in men, they were premature ejaculation (21\%), erectile dysfunction (5\%) and low sexual desire $(5 \%)$.

Reported rates of sexual dysfunction vary considerably, reflecting differences in the study population and types of dysfunction being assessed. Other studies with data for both genders show a higher prevalence of sexual dysfunction in women than in men (Ernst et al, 1993; Dunn et al, 1998) and confirm the results for the most common sexual dysfunction in both men and women.

Many factors influence the reported incidence of sexual dysfunction. The first is the method of enquiry. In a prospective study of out-patients with depression, for example, the incidence of sexual dysfunction was $14 \%$ when relying on spontaneous reporting. However, this rose to $58 \%$ when patients were questioned directly by doctors (MontejoGonzález et al, 1997). The second factor is that the expectation people have of their sexual performance and their willingness to discuss problems vary between cultures (Bhugra \& De Silva, 1993). In the third place, many terms used to define sexual dysfunction are subjective and partly dependent on ideas of what is 'normal'. Finally, temporal trends can occur as increased awareness of sexual matters and availability of treatment increase the number of those who perceive themselves to be suffering from sexual dysfunction.

\section{Sexual dysfunction in depression}

Depression is characterised by loss of interest, reduction in energy, lowered self-esteem and inability to experience pleasure: irritability and social withdrawal may impair the ability to form and maintain intimate relationships. It would be surprising if this constellation of symptoms did not produce difficulties in sexual relationships (Baldwin et al, 1997).

In an early study of 132 patients with depressive disorders, loss of sexual interest (characterised by loss of libido or decrease of sexual desire or potency) was reported by $72 \%$ of patients with unipolar disorder and $77 \%$ of those with bipolar disorder (Casper et al, 1985). Loss of sexual desire may be the presenting complaint in some patients who are found to have significant depressive symptoms only after direct questioning. In others, low sexual desire may pre-date other features of depression (SchreinerEngel \& Schiavi, 1986).
Comparative studies indicate higher levels of sexual dysfunction in patients with depression than in controls (Table 1). Although the incidence of specific types of sexual dysfunction varies across studies, loss of sexual desire may be more common than disorders of arousal and orgasm. For example, in one comparative study, changes in libido were significantly more common in patients with depression, but the prevalence of impotence, orgasmic or ejaculatory problems did not differ from controls (Mathew \& Weinman, 1982). The prospective Zurich cohort study (Ernst et al, 1993) showed that the overall prevalence of sexual problems in subjects with depression (including major depression, dysthymia and recurrent brief depression) was about twice that in controls (50\% v. 24\%). This difference encompassed emotional problems, sexual dysfunction and both decreased and increased libido. The study findings were from a group of young people (28-35 years old) and are not necessarily applicable to older age groups (Angst, 1998).

The Zurich study also compares the prevalence of sexual problems in untreated patients and patients receiving either medication ( $50 \%$ benzodiazepines, $50 \%$ antidepressants) or psychotherapy. Sexual problems were more prevalent in the 78 patients who received treatment $(62 \%)$ than in the 122 who did not (45\%) and both groups had a higher prevalence of sexual dysfunction than did the 326 controls $(26 \%)$. No statistically significant differences were found in the prevalence of any form of sexual dysfunction between patients treated with medication or psychotherapy alone (Angst, 1998).

\section{Sexual function in schizophrenia}

There have been few studies of sexual function and satisfaction in people with schizophrenia, and comparisons of untreated and treated patients are rare (Baldwin \& Birtwistle, 1997). In a comparison of successive cohorts of patients with schizophrenia, rates of marriage and fertility increased in men and women across all age groups; the authors attributed this to reduced time spent in hospital and moreflexible social attitudes (Erlenmayer-Kimmling et al, 1969). However, clinicians traditionally believed that patients who engaged in sexual relations were in danger of exacerbating their illness (Pinderhughes et al, 1972), and in many institutions sexual activity was discouraged, partly owing to fear of exploitation and pregnancy in vulnerable patients (Akhtar et al, 1977).

Although sexual delusions and somatic hallucinations can form part of the psychopathology of schizophrenia, the onset of psychosis is often associated with reduced sexual activity (Rozan et al, 1971). Persistent psychosis is also associated with 


\begin{tabular}{|c|c|c|c|c|c|}
\hline Study & $\begin{array}{l}\text { Subjects } \\
\text { with depression }\end{array}$ & Control subjects & Dysfunctions assessed & $\begin{array}{l}\text { Prevalence in } \\
\text { depression, \% }\end{array}$ & $\begin{array}{l}\text { Prevalence in } \\
\text { controls, } \%\end{array}$ \\
\hline $\begin{array}{l}\text { Casper et al, } \\
1985\end{array}$ & $\begin{array}{l}\text { Hospitalised for } \\
\text { major depressive } \\
\text { disorder } \\
\text { (unipolar: } n=85 \text {; } \\
\text { bipolar: } n=47 \text { ) }\end{array}$ & $\begin{array}{l}\text { Age- and gender- } \\
\text { matched }(n=80)\end{array}$ & $\begin{array}{l}\text { Loss of sexual interest } \\
\text { (derived from scores on } \\
\text { items } 14 \text { of HRSD, } 32 \text { of } \\
\text { VIBES, } 5 \text { of HSCL and } \\
230 \text { of SDAS-C) }\end{array}$ & $\begin{array}{l}72 \text { (unipolar) } \\
77 \text { (bipolar) }\end{array}$ & $5^{* *}$ \\
\hline $\begin{array}{l}\text { Mathew \& } \\
\text { Weinman, } \\
1982\end{array}$ & $\begin{array}{l}\text { Drug-free patients } \\
\text { with depression } \\
(n=51)\end{array}$ & $\begin{array}{l}\text { Age- and gender- } \\
\text { matched controls } \\
(n=51)\end{array}$ & $\begin{array}{l}\text { Loss of libido (defined } \\
\text { as desire to have sex) } \\
\text { Excessive libido } \\
\text { Impotence } \\
\text { Premature ejaculation } \\
\text { Delayed ejaculation } \\
\text { Lack of orgasm }\end{array}$ & $\begin{array}{l}31 \\
22 \\
35 \\
38 \\
47 \\
34\end{array}$ & $\begin{array}{r}6^{*} \\
\\
0^{*} \\
0^{1} \\
0^{1} \\
6^{1} \\
11^{1}\end{array}$ \\
\hline Angst, 1998 & $\begin{array}{l}\text { Random selection } \\
\text { from a population } \\
\text { scoring above the } \\
\text { 85th percentile on } \\
\text { SCL-90-R; } \\
\text { includes major } \\
\text { depressive } \\
\text { disorder, } \\
\text { dysthymia } \\
\text { and recurrent } \\
\text { brief depression } \\
(n=126)\end{array}$ & $\begin{array}{l}\text { Randomly } \\
\text { selected from a } \\
\text { population } \\
\text { scoring below the } \\
\text { 85th percentile } \\
\text { on SCL-90-R } \\
(n=365)\end{array}$ & $\begin{array}{l}\text { Males ( } n=16 \text { ) } \\
\text { Increased libido } \\
\text { Decreased libido } \\
\text { Sexual dysfunction } \\
\text { Emotional problems } \\
\text { Any sexual problem } \\
\text { Females ( } n=35 \text { ) } \\
\text { Increased libido } \\
\text { Decreased libido } \\
\text { Sexual dysfunction } \\
\text { Emotional problems } \\
\text { Any sexual problem }\end{array}$ & $\begin{array}{l}23 \\
26 \\
11 \\
16 \\
48\end{array}$ & $\begin{array}{r}7^{2} \\
11^{2} \\
7^{2} \\
7^{2} \\
18^{2}\end{array}$ \\
\hline \multicolumn{6}{|c|}{$\begin{array}{l}\text { HRSD, Hamilton Rating Scale for Depression; VIBES, Video Interview Behaviour Evaluation Scale; HSCL, Hopkins } \\
\text { Symptom Checklist-90; SADS-C, Schedule for Affective Disorders and Schizophrenia - Change form; SCL-90-R, } \\
\text { Symptom Checklist } 90-\text { R. } \\
\text { 1. Not significant. } \\
\text { 2. } P \text { not determined. } \\
{ }^{*} P<0.05 ;{ }^{*} P<0.01 \text {. }\end{array}$} \\
\hline
\end{tabular}

reductions in sexual interest, activity and satisfaction (Lyketsos et al, 1983). Treated and untreated male patients reported decreased sexual desire and behaviour and increased rates of premature ejaculation than did controls. In a comparison with untreated male patients, depot antipsychotic treatment increased sexual thoughts and desire but also resulted in sexual dysfunction (Aizenberg et al, 1995). In another comparison, sexual dysfunction was more common in female patients than in controls, but not in those patients with a satisfactory overall relationship with a sexual partner (Raboch, 1986).

It is unclear whether sexual dysfunction is more or less common in patients with schizophrenia than in those with other forms of mental disorder. A small survey $(n=56)$ of in-patients found that $62 \%$ of men and $25 \%$ of women with schizophrenia reported sexual or relationship problems, compared with 63$75 \%$ of men and $50-100 \%$ of women with affective disorder (Bhui et al, 1995). In a larger study $(n=173)$, sexual problems were significantly more common in patients with schizophrenia who were receiving treatment than in patients with anxiety disorders who were not receiving treatment, but they were as common as in patients with opiate dependence who were receiving methadone (Teusch et al, 1995).

\section{Neurotransmitters and sexual function}

Many neurotransmitters and hormones are thought to play a role in maintaining normal sexual function, although their precise actions are not fully understood. They include dopamine, noradrenaline, serotonin (5-hydroxytryptamine; 5-HT), acetylcholine, $\gamma$-aminobutyric acid, oxytocin, nitric oxide, arg-vasopressin, angiotensin II, gonadotrophinreleasing hormone, substance $P$, neuropeptide $Y$ and cholecystokinin. Of these, dopamine, serotonin and nitric oxide may have the most important roles in the pathophysiology and treatment of sexual dysfunction arising from antidepressant and antipsychotic drugs (Baldwin et al, 1997). 
Increased levels of central dopamine can increase sexual arousal and enhance penile erection. Centrally acting dopaminergic compounds have been shown to facilitate sexual behaviour in animal models and the dopaminergic agonist bromocriptine can reduce sexual dysfunction in men with hyperprolactinaemia associated with chronic renal failure (Ramirez et al, 1985). Dopamine antagonists, such as most antipsychotics, can reduce sexual performance both directly and indirectly through inducing hyperprolactinaemia (Segraves, 1989). Increased central serotonergic neurotransmission can reduce sexual behaviour. Activation of $5-\mathrm{HT}_{2}$ receptors mediates inhibitory actions on sexual behaviour in animal models and 5- $\mathrm{HT}_{2}$ antagonists, such as cyproheptadine, and $5-\mathrm{HT}_{1 \mathrm{a}}$ agonists, such as buspirone, can reverse sexual dysfunction induced by selective serotonin reuptake inhibitors (SSRIs).

Penile erection involves vasodilatation arising from relaxation of smooth muscle in the corpus cavernosum. The key mediator for this is nitric oxide, which acts by increasing the cellular level of the cyclic nucleotide guanosine monophosphate (cGMP). Increases in cGMP levels can be also be effected by inhibition of phosphodiesterases, which are the enzymes involved in cyclic nucleotide breakdown. Sildenafil is a phosphodiesterase-5 inhibitor that enhances nitric-oxide-mediated vasodilatation in the corpus cavernosum by inhibiting breakdown of cGMP.

\section{Sexual side-effects of conventional antipsychotics}

Treatment-emergent sexual problems have been described as 'the unspoken side-effect of antipsychotics' (Peuskens et al, 1998). A questionnaire survey of patient satisfaction with antipsychotic drug treatment found that $43 \%$ of 202 respondents reported sexual dysfunction (Wallace, 2001). Another survey suggested that doctors underestimate the sexual and menstrual adverse effects of antipsychotic drugs (Hellewell, 1998).

It is unclear whether the untoward sexual effects of antipsychotic drugs arise mainly from direct pharmacological effects (such as dopamine receptor antagonism) or from secondary endocrine disturbances. Hyperprolactinaemia associated with prolactinomata can result in loss of sexual desire, erectile failure and reduced spermatogenesis in men; in women it can lead to altered ovarian cyclic function, amenorrhoea, reduced sexual desire and hirsutism (Petty, 1999). The claim that antipsychoticinduced hyperprolactinaemia may increase the risk of osteoporosis is not yet substantiated, as little research has been performed (Dickson \& Glazer,
1999). Conventional antipsychotic drugs can increase prolactin levels to a range associated with sexual dysfunction in non-psychiatric patients, so hyperprolactinaemia is a probable explanation of some of the sexual dysfunction seen during treatment with antipsychotics. However, in many patients, the increase in prolactin levels with antipsychotic treatment is only transient. An early small $(n=27)$ study of male patients with schizophrenia found that those with erectile failure had higher prolactin levels than those without sexual problems (Arato $e t$ $a l, 1979)$. In a subsequent investigation in male and female patients, elevated prolactin levels were associated with sexual dysfunction in men and menstrual disturbances in women (Ghadirian et al, 1982). A study of sexual function in patients taking conventional neuroleptics found that hyperprolactinaemia was the main cause of sexual dysfunction in women and in men, and that dysfunction occurred in the presence of both normal and elevated prolactin levels. However, elevated prolactin levels were likely to override any other possible causes of sexual dysfunction in these individuals (Smith et al, 2002).

Treatment with butyrophenones or phenothiazines can result in loss of sexual interest. This probably results from direct effects such as dopamine receptor antagonism and secondary hyperprolactinaemia. Other adverse effects such as sedation, extrapyramidal effects and weight gain can also reduce sexual desire (Baldwin \& Birtwistle, 1997).

Erectile failure can often result from phenothiazine treatment: in one study, 38\% of men had difficulty in achieving, and $42 \%$ in maintaining, erection (Ghadirian et al, 1982). Drug-induced priapism results from $\alpha$-adrenergic blockade combined with anticholinergic activity. Antipsychotic drugs with this profile (e.g. chlorpromazine or thioridazine) can prevent detumescence but can also cause painful prolonged erection of the penis or clitoris. About $20 \%$ of cases of drug-induced priapism are due to antipsychotic drugs; the risk seems independent of dosage or duration of treatment (Patel et al, 1996).

Ejaculatory problems are a common side-effect of conventional antipsychotics. Total inhibition of ejaculation is most common (Mitchell \& Popkin, 1983) but reduced ejaculatory volume (Ghadirian et al, 1982) and 'retrograde' ejaculation are not unusual. Spontaneous ejaculation in the absence of sexual stimulation can occur with antipsychotics but this is rare (Keitner \& Selub, 1993). Antipsychotic drug treatment is often associated with qualitative changes in orgasm. For example, painful orgasm has been reported during treatment with thioridazine, trifluoperazine and haloperidol (Baldwin \& Birtwistle, 1997). 


\section{Sexual side-effects of atypical antipsychotics}

Some atypical antipsychotic drugs (e.g. quetiapine) have a notable affinity for $5-\mathrm{HT}_{2}$ receptors as well as for dopamine $\mathrm{D}_{2}$ receptors. As 5- $\mathrm{HT}_{2}$ antagonists can facilitate sexual behaviour (see below), drugs with this effect would be expected to cause fewer sexual side-effects than those without this property. A comparative study of men with schizophrenia treated with either conventional antipsychotics or clozapine found that clozapine treatment was associated with significantly better sexual functioning, as assessed by frequency of orgasm, enjoyment of sex and sexual satisfaction (Aizenberg et al, 2001). The efficacy of clozapine in relieving positive and negative symptoms as well as other aspects of psychopathology may also have favourable effects on interpersonal relationships and sexual health.

However, there are case reports of retrograde ejaculation and priapism with clozapine, risperidone and olanzapine (Rosen \& Hanno, 1992; Emes \& Milson, 1994; Deirmenjian et al, 1998; Compton et al, 2000; Songer \& Barclay, 2001).

It is uncertain whether any particular atypical antipsychotic drug is more likely to cause sexual side-effects than others. A controlled treatment study $(n=339)$ comparing olanzapine with risperidone found that sexual dysfunction was significantly less common with olanzapine (Tran et al, 1997). Quetiapine treatment is not associated with hyperprolactinaemia, which may be an advantage. A recent retrospective cross-sectional study indicates that sexual dysfunction is less common with quetiapine (18.2\%, mean dose $360.5 \mathrm{mg} /$ day) than with haloperidol (38.1\%, $10.6 \mathrm{mg} /$ day), olanzapine $(35.3 \%, 13.5 \mathrm{mg} /$ day) or risperidone $(43.2 \%$, $5.3 \mathrm{mg} /$ day) (Bobes et al, 2001). An analysis of treatment studies with amisulpride indicates similar overall rates of all forms of endocrine disorder with amisulpride and risperidone $(4 \% v .6 \%)$; the rate of erectile failure was significantly lower with amisulpride (1\% v. 5\%) (Coulouvrat \& DondeyNouvel, 1999). Both amisulpride and risperidone can cause substantial rises in prolactin levels.

\section{Sexual side-effects of antidepressants}

Treatment-emergent sexual dysfunction can occur with tricyclic antidepressants, SSRIs and monoamine oxidase inhibitors (MAOIs). Some antidepressants (bupropion, mirtazapine, moclobemide, nefazodone and reboxetine) may be associated with a relatively lower incidence of sexual dysfunction, but most data for these newer drugs come from reviews of clinical trial adverse event databases or work with healthy volunteers (Baldwin, 2001).

Few data have been published on sexual dysfunction occurring with tricyclics, although anorgasmia was common in a study of clomipramine in patients with obsessive-compulsive disorder (Monteiro et al, 1987). The majority of studies have assessed sexual dysfunction with SSRIs, but it is difficult to interpret these findings as the study designs vary considerably. For example, fluoxetine had both the highest $(75 \%)$ and the lowest $(8 \%)$ reported prevalence of treatment-emergent sexual dysfunction, one figure being derived from specific questioning about abnormal ejaculation (Patterson, 1993), the other from spontaneous reports of orgasmic problems (Zajecka et al, 1991). Comparative studies of SSRIs have generally found no significant differences between drugs, but one study reported more sexual dysfunction with sertraline than with fluvoxamine (Nemeroff et al, 1995).

Bupropion may be associated with a low incidence of adverse sexual effects, being significantly superior to sertraline in one study (Croft et al, 1999) and to SSRIs in another (Modell et al, 1997). A comparative study with nefazodone and sertraline found nefazodone (a 5- $\mathrm{HT}_{2}$ antagonist) to be significantly superior to sertraline on some measures of sexual function (Feiger et al, 1996). The findings of a randomised controlled trial comparing moclobemide (a reversible inhibitor of monoamine oxidase type A) with the tricyclic doxepin, together with a study in healthy volunteers and post-marketing surveillance, suggest that moclobemide is relatively free of adverse effects on sexual function (Baldwin, 2001).

\section{Antidepressant augmentation or switching studies}

Several studies have investigated whether SSRIassociated sexual dysfunction can be resolved by adding, or changing to, a different antidepressant. For example, a retrospective review of 16 patients who complained of sexual dysfunction during SSRI treatment found that $11(69 \%)$ rated their sexual function as much or very much improved when buspirone was added (Norden, 1994).

Mirtazapine (which also possesses 5- $\mathrm{HT}_{2}$ antagonist properties) may be useful in some patients who develop sexual dysfunction with SSRIs. In a study of 20 patients with SSRI-associated sexual dysfunction who switched to mirtazapine, sexual function improved in 9 out of 12 patients $(75 \%)$ who completed 6-weeks' treatment, although 6 patients developed irritability and 9 reported sedation (Gelenberg et al, 1998). A second study, of 11 patients who stopped SSRIs because of sexual problems, 
found that mirtazapine did not result in the reemergence of sexual dysfunction (Koutouvidis et al, 1999). These observations are supported by findings in a group of 25 out-patients with depression, indicating that mirtazapine had beneficial effects on sexual function (Boyarsky et al, 1999).

The largest body of data is for bupropion, where the findings of one augmentation study and two substitution studies suggest that bupropion can ameliorate SSRI-induced sexual dysfunction (Baldwin, 2001). However, not all data are consistent. A retrospective review of 27 patients found that sexual dysfunction occurred in 11 patients $(41 \%)$ when they were receiving combination bupropionSSRI treatment, which was not significantly different from the rate $(52 \%)$ when they were taking either agent alone (Bodkin et al, 1997). A recent augmentation study with bupropion ( $150 \mathrm{mg} /$ day) indicates that it can be usefully combined with venlafaxine, paroxetine or fluoxetine (Kennedy et al, 2002).

\section{Treatment of psychotropic- induced sexual dysfunction}

Sexual dysfunction should be assessed sensitively and treatment tailored to individual needs and circumstances. Assessment of a patient who complains of sexual difficulties while taking a psychotropic drug involves the detailed evaluation of a range of factors (Box 1). Several strategies may be beneficial in treatment, including:

- waiting for the development of tolerance

- reduction in dosage

- delaying the taking of the drug until after sexual activity

- 'drug holidays'

- adjuvant treatments

- changing to a different psychotropic drug

- behavioural strategies to improve sexual technique

- individual psychotherapy

- couple therapy.
The role of psychological approaches is outside the scope of this article. The choice of a particular strategy is determined, among other factors, by considering the type and severity of the dysfunction, the nature of the psychiatric diagnosis, the current mental state of the patient, the potential risks of stopping treatment, the risk of untoward drug interactions and the presence or absence of a sexual partner.

Drug holidays, involving brief interruptions of treatment, have been advocated as an approach to SSRI-induced sexual dysfunction (Rothschild, 1995). However, this puts the patient at risk of discontinuation symptoms and possible relapse of depression or schizophrenia. Furthermore, a drug holiday is possible only with drugs with a short half-life. Thus, it is not appropropriate with fluoxetine, for example, where sexual side-effects may not resolve until a few weeks after stopping treatment.

Many adjuvant compounds have been advocated for relieving sexual dysfunction associated with antidepressant or antipsychotic drug treatment, including amantadine, buspirone, cyproheptadine, dexamphetamine, Ginkgo biloba, granisetron, mianserin, neostigmine, olanzapine, prostaglandin $\mathrm{E}$ (by intracavernosal injection), sildenafil and yohimbine. However, the results of placebo-controlled studies in this area have generally failed to distinguish between active treatments and placebo. It is wise to be cautious when using unfamiliar treatments. A recent small $(n=19)$ placebo-controlled augmentation study with Ginkgo biloba found no difference between treatments in reversing sexual dysfunction associated with antidepressant treatment (Kang et al, 2002). Another placebo-controlled study found no significant advantage for mirtazapine, yohimbine or olanzapine in relieving sexual dysfunction when taking SSRIs (Michelson et al, 2000).

It seems likely that sildenafil may come to have a role in relieving sexual dysfunction associated with psychotropic drugs. In a sub-group of 136 patients with depression included within the placebocontrolled clinical trial database, $76 \%$ described improvements with sildenafil, compared with $18 \%$ of the group who received placebo (Price, 1999). In

\section{Box 1 Assessment of sexual dysfunction in a patient taking a psychotropic drug}

Clinical feature

Sexual function before mental health problems

Severity of primary psychiatric disorder

Severity of comorbid psychiatric disorder

Presence of comorbid physical illness

Prescribed psychotropic medication

Prescribed medication for physical illness

Over-the-counter or illicit drug use

Overall relationship with sexual partner
Relevant factor

Long-standing erectile failure

Current mild depressive episode

Current alcohol dependence

Hypertension

Fluoxetine

Atenolol

Benzodiazepine misuse

Frequent arguments and separations 
an open study, sildenafil was effective in 10 out of 14 patients with antidepressant drug-induced sexual dysfunction (Fava et al, 1998). The benefits of sildenafil may also apply to patients with schizophrenia, as a case report has described successful treatment of reduced sexual desire and erectile failure in a man with schizophrenia who was receiving antipsychotic drugs (Benatov et al, 1999). A recent double-blind placebo-controlled study of 160 men with erectile dysfunction and comorbid minor depression found that the response of erectile problems to sildenafil treatment was associated with a significant reduction in depressive symptoms (Seidman et al, 2001).

\section{Conclusions}

The key points of this article are summarised in Box 2. Accurate assessment of sexual function in depression or schizophrenia is subject to many difficulties, including the fact that there are few available data on prevalence of sexual dysfunction in the general population and the effects of antidepressant and antipsychotic drugs. Obtaining accurate data on an intimate subject is potentially prone to underreporting unless careful attention is paid to the method of data collection. Until data from rigorous, controlled, comparative studies are available, the perceived likelihood of sexual sideeffects should not unduly influence the choice of psychotropic drug, and prescribing decisions should be made on an assessment of the overall balance of the benefits and risks of treatment.

\section{Box 2 Key points}

Sexual dysfunction is common in patients with depression or schizophrenia, but is often not reported to doctors; it may be an unrecognised cause of non-adherence to treatment

Some antidepressant drugs (moclobemide, nefazodone, mirtazapine) are less likely to cause sexual problems than others and may be useful when patients have developed treatment-emergent sexual dysfunction

Certain atypical antipsychotics may cause fewer sexual problems than conventional ones, but whether this is due to a reduced incidence of hyperprolactinaemia remains uncertain

Treatment of established sexual dysfunction in a patient with depression or schizophrenia usually requires the combination of pharmacological and psychological approaches

\section{References}

Aizenberg, D., Zemishlany, Z., Dorfman, E. P., et al (1995) Sexual dysfunction in male schizophrenic patients. Journal of Clinical Psychiatry, 56, 137-141.

-, Modai, I., Landa, A., et al (2001) Comparison of sexual dysfunction in male schizophrenic patients maintained on treatment with classical antipsychotics versus clozapine. Journal of Clinical Psychiatry, 62, 541-544.

Akhtar, S., Crocker, E., Dickey, N., et al (1977) Overt sexual behaviours among psychiatric inpatients. Diseases of the Nervous System, 38, 359-361.

American Psychiatric Association (1994) Diagnostic and Statistical Manual of Mental Disorders (4th edn) (DSM-IV). Washington, DC: American Psychiatric Association.

Angst, J. (1998) Sexual problems in healthy and depressed patients. International Clinical Psychopharmacology, 13 (suppl. 6), S1-S3.

Arato, M., Erdos, A. \& Polgar, M. (1979) Endocrinological changes in patients with sexual dysfunction under longterm neuroleptic treatment. Pharmakopsychiatrie Neuropsychopharmakologie, 12, 426-431.

Baldwin, D. S. (2001) Depression and sexual dysfunction. British Medical Bulletin, 57, 81-99.

- \& Birtwistle, J. (1997) Schizophrenia, antipsychotic drugs and sexual function. Primary Care Psychiatry, 3, 115-123.

- Thomas, S. C. \& Birtwistle, J. (1997) Effects of antidepressant drugs on sexual function. International Journal of Psychiatry in Clinical Practice, 1, 47-58.

Benatov, R., Reznik, I. \& Zemishlany, Z. (1999) Sildenafil citrate (Viagra) treatment of sexual dysfunction in a schizophrenic patient. European Psychiatry, 14, 353-355.

Bhugra, D. \& De Silva, P. (1993) Sexual dysfunction across cultures. International Review of Psychiatry, 5, 243-252.

Bhui, K., Puffet, A. \& Herriot, P. (1995) A survey of sexual problems amongst psychiatric inpatients. Social Psychiatry and Psychiatric Epidemiology, 30, 73-77.

Bobes, J., Rejas, J., Garcia, M., et al (2001) Frequency and Management of Sexual Dysfunction with Antipsychotic Drugs in Schizophrenic Patients: Results from the EIRE Study. New Orleans, LA: American Psychiatric Association.

Bodkin, J. A., Lasser, R. A., Wines, J. D., et al (1997) Combining serotonin reuptake inhibitors and bupropion in partial responders to antidepressant monotherapy. Journal of Clinical Psychiatry, 58, 137-145.

Boyarsky, B. K., Haque, W., Rouleau, M. R., et al (1999) Sexual functioning in depressed outpatients taking mirtazapine. Depression and Anxiety, 9, 175-179.

Casper, R. C., Redmond, E., Katz, M. M., et al (1985) Somatic symptoms in primary affective disorders: presence and relationship to the classification of depression. Archives of General Psychiatry, 42, 1098-1104.

Compton, M. T., Saldivia, A. \& Berry, S. A. (2000) Recurrent priapism during treatment with clozapine and olanzapine. American Journal of Psychiatry, 157, 659.

Coulouvrat, C. \& Dondey-Nouvel, L. (1999) Safety of amisulpride (Solian): a review of 11 clinical studies. International Clinical Psychopharmacology, 14, 209-218.

Croft, H., Settle, E. Jr., Houser, T., et al (1999) A placebocontrolled comparison of the antidepressant efficacy and effects on sexual functioning of sustained-release bupropion and sertraline. Clinical Therapeutics, 21, 643658.

Deirmenjian, J. H., Erhart, S. M., Wirshing, D. A., et al (1998) Olanzapine-induced reversible priapism: a case report. Journal of Clinical Psychopharmacology, 18, 351-353.

Dickson, R. A. \& Glazer, W. M. (1999) Neuroleptic-induced hyperprolactinaemia. Schizophrenia Research, 35, S75-S86.

Dunn, K. M., Croft, P. R. \& Hackett, G. I. (1998) Sexual problems: a study of the prevalence and need for health care in the general population. Family Practice, 15, 519-524.

Emes, C. E. \& Milson, R. C. (1994) Risperidone-induced priapism. Canadian Journal of Psychiatry, 39, 315-316.

Erlenmayer-Kimmling, L., Nicol, S., Rainer, J. D., et al (1969) Changes in fertility rates of schizophrenic patients in New York State. American Journal of Psychiatry, 125, 88-99. 
Ernst, C., Foldenyi, M. \& Angst, J. (1993) The Zurich Study: XXI. Sexual dysfunctions and disturbances in young adults. European Archives of Psychiatry and Clinical Neuroscience, 243, 179-188.

Fava, M., Rankin, M. A., Alpert, J. E., et al (1998) An open trial of sildenafil in antidepressant-induced sexual dysfunction. Psychotherapy and Psychosomatics, 67, 328331.

Feiger, A., Kiev, A., Shrivastava, R. K., et al (1996) Nefazodone versus sertraline in outpatients with major depression: focus on efficacy, tolerability and effects on sexual function and satisfaction. Journal of Clinical Psychiatry, 57 (suppl. 2), S53-S62.

Gelenberg, A. J., Laukes, C., McGahuey, C., et al (1998) Mirtazapine substitution in SSRI-induced sexual dysfunction (abstract). Biological Psychiatry, 43, 104S.

Ghadirian, A. M., Chouinard, G. \& Annable, L. (1982) Sexual dysfunction and plasma prolactin levels in neuroleptictreated schizophrenic outpatients. Journal of Nervous and Mental Disease, 170, 463-467.

Hellewell, J. S. E. (1998) Antipsychotic tolerability: the attitudes and perceptions of medical professionals, patients and caregivers towards the side effects of antipsychotic therapy (abstract). European Neuropsychopharmacology, 8, S248.

Kang, B.-J., Lee, S.-J., Kim, M.-D., et al (2002) A placebocontrolled, double-blind trial of Ginkgo biloba for antidepressant-induced sexual dysfunction. Human Psychopharmacology: Clinical and Experimental, 17, 279284

Keitner, G. I. \& Selub, S. (1993) Spontaneous ejaculations and neuroleptics. Journal of Clinical Psychopharmacology, 3, 34-36.

Kennedy, S. H., McCann, S. M., Masellis, M., et al (2002) Combining bupropion SR with venlafaxine, paroxetine or fluoxetine: a preliminary report on pharmacokinetic, therapeutic and sexual dysfunction effects. Journal of Clinical Psychiatry, 63, 181-186.

Koutouvidis, N., Pratikakis, M. \& Fotiadou, A. (1999) The use of mirtazapine in a group of 11 patients following poor compliance to selective serotonin reuptake inhibitor treatment due to sexual dysfunction. International Clinical Psychopharmacology, 14, 253-255.

Laumann, E. O., Park, A. \& Rosen, R. C. (1999) Sexual dysfunction in the United States: prevalence and predictors. JAMA, 281, 537-544.

Lyketsos, G. C., Sakka, P. \& Mailis, A. (1983) The sexual adjustment of chronic schizophrenics: a preliminary study. British Journal of Psychiatry, 143, 376-382.

Mathew, R. J. \& Weinman, M. L. (1982) Sexual dysfunctions in depression. Archives of Sexual Behavior, 11, 323-325.

Michelson, D., Bancroft, J., Targum, S., et al (2000) Female sexual dysfunction associated with antidepressant administration: a randomized, placebo-controlled study of pharmacologic intervention. American Journal of Psychiatry, 157, 239-243.

Mitchell, J. \& Popkin, M. (1983) The pathophysiology of sexual dysfunction associated with antipsychotic drug therapy in males: A review. Archives of Sexual Behavior, 12, 173-183.

Modell, J. G., Katholi, C. R., Modell, J. D., et al (1997) Comparative sexual side effects of bupropion, fluoxetine, paroxetine, and sertraline. Clinical Pharmacology and Therapeutics, 61, 476-487.

Monteiro, W. O., Noshirvani, H. F., Marks, I. M., et al (1987) Anorgasmia from clomipramine in obsessive-compulsive disorder: a controlled trial. British Journal of Psychiatry, 151, 107-112.

Montejo-González, A. L., Liorca, G., Izquierdo, J. A., et al (1997) SSRI-induced sexual dysfunction: fluoxetine, paroxetine, sertraline and fluvoxamine in a prospective, multicenter, and descriptive clinical study of 344 patients. Journal of Sex and Marital Therapy, 23, 176-194.

Nathan, S. G. (1986) The epidemiology of the DSM-III psychosexual dysfunctions. Journal of Sex and Marital Therapy, 12, 267-281.
Nemeroff, C. B., Ninan, P. T., Ballenger, J., et al (1995) Doubleblind multicenter comparison of fluvoxamine versus sertraline in the treatment of depressed outpatients. Depression, 3, 163-169.

Norden, M. J. (1994) Buspirone treatment of sexual dysfunction associated with selective serotonin reuptake inhibitors. Depression, 2, 109-112.

Patel, A. G., Mukherji, K. \& Lee, A. (1996) Priapism associated with psychotropic drugs. British Journal of Hospital Medicine, 55, 315-319.

Patterson, W. M. (1993) Fluoxetine-induced sexual dysfunction. Journal of Clinical Psychiatry, 54, 71.

Petty, R. G. (1999) Prolactin and antipsychotic medications: mechanism of action. Schizophrenia Research, 35 (suppl.), S67-S73.

Peuskens, J., Sienaert, P. \& De Heft, M. (1998) Sexual dysfunction: the unspoken side effect of antipsychotics. European Psychiatry, 13 (suppl. 1), 23S-30S.

Pinderhughes, C. A., Grace, E. B. \& Reyna, L. J. (1972) Psychiatric disorders and sexual functioning. American Journal of Psychiatry, 128, 1276-1283.

Price, D. (1999) Sildenafil citrate (Viagra) in the treatment of erectile dysfunction in patients with common concomitant conditions (Sildenafil Study Group). International Journal of Clinical Practice, 102, 21-23.

Raboch, J. (1986) Sexual development and life of psychiatric female patients. Archives of Sexual Behavior, 15, 341-353.

Ramirez, G., Butcher, D. E., Newton, J. L., et al (1985) Bromocriptine and the hypothalamic hypophyseal function in patients with chronic renal failure on chronic haemodialysis. American Journal of Kidney Diseases, 6, 111118.

Rosen, S. I. \& Hanno, P. M. (1992) Clozapine-induced priapism. Journal of Urology, 148, 876-877.

Rothschild, A. J. (1995) Selective serotonin reuptake inhibitorinduced sexual dysfunction: efficacy of a drug holiday. American Journal of Psychiatry, 152, 514-516.

Rozan, G., Tuchin, T. \& Kurland, M. (1971) Some implications of sexual activity for mental illness. Mental Hygiene, 55, 318-323.

Schreiner-Engel, P. \& Schiavi, R. C. (1986) Lifetime psychopathology in individuals with low sexual desire. Journal of Nervous and Mental Disease, 174, 646-651.

Segraves, R. T. (1989) Effects of psychotropic drugs on human erection and ejaculation. Archives of General Psychiatry, 46, 275-284.

Seidman, S. N., Roose, S. P., Menza, M. A., et al (2001) Treatment of erectile dysfunction in men with depressive symptoms: results of a placebo-controlled trial with sildenafil citrate. American Journal of Psychiatry, 158, 16231630 .

Smith, S., O'Keane, V. \& Murray, R. (2002) Sexual dysfunction in patients taking conventional antipsychotic medication. British Journal of Psychiatry, 181, 49-55.

Songer, D. A. \& Barclay, J. C. (2001) Olanzapine-induced priapism. American Journal of Psychiatry, 158, 2087-2088.

Teusch, L., Scherbaum, N., Bohme, H., et al (1995) Different patterns of sexual dysfunctions associated with psychiatric disorders and psychopharmacological treatment. Results of an investigation by semistructured interview of schizophrenic and neurotic patients and methadonesubstituted opiate addicts. Pharmacopsychiatry, 28, 8492.

Tran, P. V., Hamilton, S. H., Kuntz, A. J., et al (1997) Doubleblind comparison of olanzapine versus risperidone in the treatment of schizophrenia and other psychotic disorders. Journal of Clinical Psychopharmacology, 17, 407-418.

Wallace, M. (2001) Real progress - The patient's perspective. International Clinical Psychopharmacology, 16 (suppl. 1), S21-S24.

World Health Organization (1992) International Classification of Diseases, 10th Revision (ICD-10) Geneva: WHO.

Zajecka, J., Fawcett, J., Schaff, M., et al (1991) The role of serotonin in sexual dysfunction: fluoxetine-associated orgasm dysfunction. Journal of Clinical Psychiatry, 52, 6668. 


\section{Multiple choice questions}

1 The following may be helpful adjuvant treatments for patients with SSRI-induced delayed ejaculation:

a buspirone

b sildenafil

c moclobemide

d cyproheptadine

e the squeeze technique.

2 Antipsychotic-induced hyperprolactinaemia can result in the following problems:

a unilateral gynaecomastia

b infertility

c vaginismus

d priapism

e amenorrhoea.

3 Brief drug holidays may be a useful approach to SSRI-induced sexual dysfunction when:

a the patient is receiving fluoxetine

b discontinuation symptoms have proved troublesome

c previously abstinent patients wish to resume their opiate habit

$\mathrm{d}$ the patient is suicidal

e the patient is undergoing sertraline treatment.

4 The problem of sexual dysfunction in patients with depression:

a is a fiction created by the pharmaceutical industry

b may be an unrecognised cause of treatment nonadherence c is relevant only to patients in intimate relationships

$\mathrm{d}$ can be elicited by sensitive direct questioning

e is usually due to the presence of comorbid physical illness.

5 Erectile failure in a middle-aged man with chronic schizophrenia and diabetes mellitus, undergoing phenothiazine treatment:

a may improve if the patient is switched to quetiapine

$b$ can be associated with delusions of control

c can be caused by peripheral vascular disease

d may be due to depression

e can respond to sildenafil treatment.

\section{Free speech...}

What do you think about Advances in Psychiatric Treatment - its usefulness for CPD, the new abstracts, the topics covered, the design, PDA downloads?

Go to:

www.rcpsych.ac.uk/bulletin/apt/apply.htm to join the $A P T$ discussion forum and... have your say about APT and CPD! 